\title{
Crescimento e produtividade de cultivares de tomate cereja utilizando substratos de base ecológica
}

Francis Junior Soldateli, Carine Borges Batista, Filipe Godoy, Anderson Chuquel Mello, Franciéle dos Santos Soares, Miréli Duarte Bergmann, Luciana Zago Ethur

Universidade Federal do Pampa - UNIPAMPA. E-mail: francisjrsoldateli@gmail.com

\section{Resumo}

Objetivou-se avaliar a influência de substratos no crescimento e produtividade de cultivares de tomateiro cereja Cascade e Samambaia em ambiente protegido. Adotou-se delineamento experimental inteiramente casualizado, com seis tratamentos e quatro repetições. Os tratamentos consistiram de seis substratos, resultantes da combinação de solo (SC), esterco bovino (EB), casca de arroz (CA) e cinza de casca de arroz (CC): S1 - 70\% SC + 10\% EB + 10\% CA + 10\% CC; S2 - 60\% SC + 20\% EB + 10\% CA + 10\% CC; S3 - 50\% SC + 30\% $E B+10 \% C A+10 \% C C ; S 4-60 \%$ SC $+30 \% E B+10 \% C A ; S 5-70 \%$ SC $+20 \%$ EB $+10 \%$ CA; e S6 - 100\% SC. Avaliou-se parâmetros de crescimento, produtividade e desenvolvimento das plantas. $\mathrm{O}$ crescimento e a produtividade de tomateiro cereja modificaram-se conforme as características dos substratos. $\mathrm{O}$ substrato composto por solo não se mostrou eficiente, apresentando os menores valores para todos os parâmetros vegetativos e reprodutivos estudados. Os substratos elaborados a base de resíduos alternativos de base ecológica mostram-se como fontes alternativas e interessantes no cultivo do tomateiro visando o reaproveitamento da matéria e a sustentabilidade do sistema produtivo.

Palavras-chave: ambiente protegido; classificação de frutos; Solanum lycopersicum var. cerasiforme.

\section{Growth and productivity of cherry tomato cultivars using ecological based substrates}

\begin{abstract}
The objective of this study was to evaluate the influence of substrates on the growth and yield of Cascade and Samambaia cherry tomato cultivars under protected environment. A completely randomized experimental design with six treatments and four replications was adopted. The treatments consisted of six substrates resulting from the combination of soil (CS), bovine manure (BM), rice husk (RH) and rice hull ash (RA), in the proportions: $\mathrm{S} 1-70 \% \mathrm{SC}+10 \% \mathrm{BM}+10 \% \mathrm{RH}+10 \% \mathrm{RA}$; S2 - 60\% SC $+20 \% \mathrm{BM}+10 \% \mathrm{RH}+10 \%$ RA; S3 - 50\% SC + 30\% BM + 10\% RH + 10\% RA; S4 - 60\% SC + 30\% BM + 10\% RH; S5 - 70\% SC + 20\% BM + $10 \% \mathrm{RH}$; and $\mathrm{S} 6-100 \% \mathrm{SC}$. Plant growth, yield and development parameters were evaluated. Cherry tomato growth and yield changed according to the substrate characteristics. The substrate composed by soil was not efficient, presenting the lowest values for all the vegetative and reproductive parameters studied. The substrates made from alternative ecologically based residues are interesting and alternative sources for tomato cultivation aiming at the reuse of the matter and the sustainability of the production system.
\end{abstract}

Keywords: protected environment; classification of fruits; Solanum lycopersicum var. cerasiforme.

\section{Introdução}

A crescente demanda por hortaliças de elevada qualidade, com procedência e cultivo sustentável, tornou-se um fator influente no mercado produtor. Dentre as diversas hortaliças exploradas comercialmente, o tomate cereja (Solanum lycopersicum var. cerasiforme) ganha destaque na dieta humana. O tomateiro é amplamente utilizado devido à sua versatilidade culinária e valor nutricional, pois apresenta 
diversos compostos benéficos a manutenção do organismo humano (BARANKEVICZ et al., 2015). Além disto, mostra-se instigante aos consumidores, presumivelmente, em virtude de suas propriedades organolépticas exóticas.

O tomateiro do grupo cereja mostra-se uma excelente alternativa de renda para o pequeno e médio produtor, devido ao seu elevado valor agregado e simplicidade nos tratos culturais. Destaca-se pela elevada rusticidade, tolerância a pragas e doenças, produtividade, rentabilidade e boa aceitação dos consumidores (LUCINI et al., 2016; ZANIN et al., 2018; DIAS et al., 2019). Entretanto, o cultivo de minitomates é realizado em ambiente protegido, geralmente em recipientes, resultando em elevado custo de produção e adoção de distintos modelos de produção associados a utilização de diferentes substratos, tratos culturais e manejos fitossanitários (MACIEL et al., 2016). Logo, técnicas agronômicas sustentáveis e ambientalmente corretas devem ser exploradas para elevar a economicidade do sistema.

A escolha do substrato adequado é um fator primordial no momento da implantação da cultura, devendo-se a este à responsabilidade de sustentar a planta, proporcionar suporte físico, além de atender as suas demandas químicas e biológicas. Conseguinte, plântulas raquíticas, debilitadas e de baixo vigor, irão resultar em plantas desuniformes, pouco produtivas e mais suscetíveis a ocorrência de pragas e moléstias, comprometendo todo o cultivo (SANTOS et al., 2017). Mesmo havendo substratos comerciais mais recomendados para o cultivo de determinadas espécies, tem-se procurado introduzir novas tecnologias sustentáveis de produção que supram à necessidade e ao mesmo tempo sejam acessíveis as condições econômicas dos produtores (FERREIRA et al., 2018). Nesse sentido, a utilização de substratos oriundos de resíduos alternativos de base ecológica surge como fonte alternativa para a produção (ZEIST et al., 2019).

Apesar da produção de tomates convencionais ser predominante nos sistemas de cultivo, a agricultura orgânica mostra-se relevante na diversificação e qualidade de produtos vegetais. Por tratar-se de pequenas áreas, o cultivo orgânico apresenta um mercado em franca expansão e como forma de agregar valor ao produto, sendo que, a maioria das áreas de produção é restrita e familiar (SCALCO et al., 2017). A produção de tomate orgânico, quando comparado ao da produção convencional, apresenta um custo $17,2 \%$ menor e uma rentabilidade $113,6 \%$ maior (LUZ et al., 2007), mesmo apresentando maior taxa de frutos pequenos em comparação com o sistema convencional (NASCIMENTO et al., 2013). Logo, para expansão da produção e oferta de tomates com características dimensionais e organolépticas atrativas aos consumidores, é necessário diversificar os sistemas produtivos (COSTA et al., 2018a). Desta forma, é preciso intensificar pesquisas que visem a utilização de substratos alternativos, cujas características diferem-se grandemente das do solo, não existindo assim, substratos ou compostos destes, específicos para o cultivo de tomate.

$$
\text { Considerando as informações }
$$

supracitadas, objetivou-se avaliar a influência de substratos alternativos no crescimento e produtividade das cultivares de tomateiro cereja Cascade e Samambaia em ambiente protegido.

\section{Material e Métodos}

$O$ experimento foi conduzido na casa de vegetação da Universidade Federal do Pampa, na cidade de Itaqui, localizada na fronteira oeste do Rio Grande do Sul (RS), Brasil, com coordenadas de $29^{\circ} 09^{\prime} 21.68^{\prime \prime} \mathrm{S}$ de latitude e $56^{\circ} 33^{\prime} 02.58^{\prime \prime} \mathrm{W}$ de longitude, com altitude de $74 \mathrm{~m}$. Segundo a classificação climática de Koppen-Geiger, o clima é do tipo $\mathrm{Cfa}$, subtropical sem estação seca definida.

O delineamento experimental utilizado foi o inteiramente casualizado, com seis tratamentos e quatro repetições. Os tratamentos consistiram em seis substratos, os quais resultaram da combinação de casca de arroz (CA), cinza de casca de arroz (CC), esterco bovino curtido (EB) e solo (SC), nas proporções volumétricas: $\mathrm{S} 1-70 \% \mathrm{SC}+10 \% \mathrm{~EB}+10 \% \mathrm{CA}+$ $10 \%$ CC; S2 - 60\% SC + 20\% EB + 10\% CA + 10\% CC; S3 - 50\% SC + 30\% EB + 10\% CA + 10\% CC; S4 $60 \% \mathrm{SC}+30 \% \mathrm{~EB}+10 \% \mathrm{CA} ; \mathrm{S} 5-70 \% \mathrm{SC}+20 \% \mathrm{~EB}$ $+10 \%$ CA; e S6 - $100 \%$ SC. A CA e CC foram obtidas como resíduo do processo de beneficiamento do arroz, O EB obtido após compostagem dos dejetos dos animais e o SC coletado no Campus Itaqui, este classificado como Plintossolo Argilúvico distrófico (EMBRAPA, 2018). A unidade experimental foi composta por dois vasos, contendo uma planta por vaso.

$\mathrm{Na}$ produção de mudas utilizaram-se sementes de tomate cereja das cultivares Cascade (Feltrin ${ }^{\circledR}$ ) e Samambaia (Topseed ${ }^{\circledR}$ ) sem 
tratamento químico. A semeadura foi realizada em bandejas de poliestireno expandido, com 128 células e o transplante das mudas foi realizado quando possuíam cinco folhas definitivas, em vasos com capacidade de volume de cinco litros, altura de $20 \mathrm{~cm}$, diâmetro de boca de $15 \mathrm{~cm}$, contendo os substratos referentes aos tratamentos. Cada substrato foi caracterizado quimicamente, sendo os valores das propriedades avaliadas na caracterização dos componentes expressos na Tabela 1. As plantas foram submetidas a regas diárias, conforme a demanda hídrica, iniciando-se logo após o transplante, ademais, não foi realizado aplicação de fertilizantes adicionais.

Tabela 1. Composição química dos substratos utilizados no cultivo de tomates do grupo cereja, em ambiente protegido, Itaqui, RS, 2018.

\begin{tabular}{|c|c|c|c|c|c|c|c|c|c|c|c|c|c|}
\hline & Argila & M.O. & $\ldots .$. & $\begin{array}{c}\mathrm{pH} \\
\text { água }\end{array}$ & $\begin{array}{l}\text { Índice } \\
\text { SMP }\end{array}$ & $\begin{array}{l}P \\
. \mathrm{mg} \mathrm{d}\end{array}$ & $K$ & $\mathrm{Al}$ & $\ldots \mathrm{cmc}$ & $\mathrm{Mg}$ & $\mathrm{H}+\mathrm{Al}$ & $\begin{array}{l}\text { CTC } \\
\mathrm{pH} 7\end{array}$ & $\mathrm{Ca} / \mathrm{Mg}$ \\
\hline S1 & 20 & 3,4 & 67,6 & 5,3 & 6,4 & 86,9 & 284 & 0,1 & 3,20 & 1,96 & 2,8 & 8,7 & 1,6 \\
\hline S2 & 19 & 2,5 & 75,9 & 5,7 & 6,6 & 273,0 & 500 & 0,0 & 2,91 & 2,87 & 2,2 & 9,3 & 1,0 \\
\hline S3 & 18 & 2,7 & 80,1 & 5,8 & 6,6 & 359,2 & 548 & 0,0 & 3,46 & 3,79 & 2,2 & 10,8 & 0,9 \\
\hline S4 & 19 & 3,3 & 73,3 & 5,7 & 6,3 & 383,5 & 544 & 0,0 & 3,25 & 3,87 & 3,1 & 11,6 & 0,8 \\
\hline S5 & 20 & 2,5 & 73,7 & 5,7 & 6,4 & 188,5 & 404 & 0,0 & 3,90 & 3,02 & 2,8 & 10,8 & 1,3 \\
\hline S6 & 22 & 1,9 & 53,7 & 4,8 & 5,7 & 6,7 & 120 & 0,3 & 5,38 & 1,46 & 6,2 & 13,3 & 3,7 \\
\hline
\end{tabular}

S1- $70 \%$ solo (SC) + 10\% esterco bovino (EB) + 10\% casca de arroz (CA) + 10\% casca de arroz carbonizada (CC); S2- $60 \%$ SC $+20 \% E B+10 \% C A+10 \%$ CC; S3- $50 \%$ SC + 30\% EB + 10\% CA + 10\% CC; S4- 60\% SC + 30\% EB + 10\% CA; S5- $70 \%$ SC $+20 \% \mathrm{~EB}+10 \% \mathrm{CA} ; \mathrm{S} 6-100 \% \mathrm{SC}$.

A condução das plantas foi realizada por meio de haste vertical, conforme procedido por Zeist et al., (2018). Os vasos foram distribuídos em espaçamento de $50 \times 40 \mathrm{~cm}$. Ao decorrer do ciclo, semanalmente realizou-se remoção das brotações laterais e aos 103 dias após o transplante removeu-se a dominância apical.

Aos 75 dias após o transplante, avaliou-se os caracteres de altura da planta - determinada com auxílio de régua graduada; e número de folhas - determinada por meio da contagem do número de folhas presentes nas plantas. Quando os frutos apresentavam $3 / 4$ da coloração vermelho claro, foram coletados e avaliados quanto às características número de frutos por planta determinado por meio do número total de frutos por planta; diâmetro vertical e horizontal dos frutos - determinado com auxílio de paquímetro, com medição dos frutos; e massa média dos frutos - determinada por meio da relação entre a produção por planta e o número de frutos.

Os dados obtidos foram submetidos à análise de variância pelo teste $\mathrm{F}$ e as médias foram comparadas pelo teste de Tukey, a $5 \%$ de probabilidade de erro, utilizando o programa estatístico Sisvar ${ }^{\circledast}$ (FERREIRA, 2008).

\section{Resultados e Discussão}

Os menores valores para a altura de planta, foram obtidos no substrato $\mathrm{S} 6$, composto somente por solo, apresentando diferença mínima de 30,7 e $36,6 \%$, entre os demais tratamentos compostos por resíduos alternativos de base ecológica, para as cultivares Cascade e Samambaia, respectivamente (Tabela 2). 0 resultado encontrado neste substrato, remete aos aspectos nutricionais limitantes para o crescimento do tomateiro, em suma, ao teor de nitrogênio (Tabela 1).

A utilização de fontes de matéria orgânica resulta no acréscimo de nitrogênio presente no solo, além de elevar a biomassa microbiana, sendo que, substratos compostos por vermicomposto e esterco de galinha mostram-se mais efetivos no aumento da estatura de tomate cereja quando comparado a aplicação de fontes minerais deste nutriente (WANG et al., 2017). Em cultivo com substratos orgânicos, a base de esterco bovino, vermicomposto e vermiculita, os tomateiros não apresentaram diferenças significativas entre as distintas proporções dos componentes para a variável altura (COSTA et al., 2018b). Os valores obtidos justificam a influência da presença de matéria orgânica frente à quantidade suficiente de cargas iônicas, porosidade, retenção de umidade e nutrientes prontamente disponíveis para promover o crescimento. 
Tabela 2. Altura de planta (ALT) e número de folhas (NFO) de tomate cereja, cultivares Cascade e Samambaia, cultivadas em substratos alternativos (S), Itaqui, RS, 2018.

\begin{tabular}{ccccc}
\hline \multirow{2}{*}{ Substratos } & \multicolumn{2}{c}{ Cascade } & \multicolumn{2}{c}{ Samambaia } \\
\cline { 2 - 5 } & $\begin{array}{c}\text { ALT } \\
(\mathrm{cm})\end{array}$ & NFO & $\begin{array}{c}\text { ALT } \\
(\mathrm{cm})\end{array}$ & NFO \\
\hline S1 & $76,68 \mathrm{a}^{*}$ & $15,63 \mathrm{a}$ & $104,80 \mathrm{a}$ & $15,00 \mathrm{a}$ \\
S2 & $79,42 \mathrm{a}$ & $15,88 \mathrm{a}$ & $107,06 \mathrm{a}$ & $16,00 \mathrm{a}$ \\
S3 & $78,25 \mathrm{a}$ & $15,63 \mathrm{a}$ & $111,35 \mathrm{a}$ & $16,88 \mathrm{a}$ \\
S4 & $76,28 \mathrm{a}$ & $15,75 \mathrm{a}$ & $109,23 \mathrm{a}$ & $16,38 \mathrm{a}$ \\
S5 & $79,71 \mathrm{a}$ & $16,25 \mathrm{a}$ & $115,78 \mathrm{a}$ & $17,00 \mathrm{a}$ \\
S6 & $58,35 \mathrm{~b}$ & $11,38 \mathrm{~b}$ & $76,73 \mathrm{~b}$ & $10,00 \mathrm{~b}$ \\
\hline CV (\%) & 7,87 & 7,03 & 10,38 & 9,47 \\
\hline
\end{tabular}

*Médias seguidas de mesma letra minúscula na coluna não diferem entre si pelo teste de Tukey a $5 \%$ de probabilidade. S1- $70 \%$ solo $(\mathrm{SC})+10 \%$ esterco bovino (EB) $+10 \%$ casca de arroz (CA) $+10 \%$ casca de arroz carbonizada (CC); S2- $60 \%$ SC + 20\% EB + 10\% CA + 10\% CC; S3- 50\% SC + 30\% EB + 10\% CA + 10\% CC; S4- 60\% SC + 30\% $E B+10 \% C A ; S 5-70 \% S C+20 \% E B+10 \% C A ; S 6-100 \%$ SC.

Quanto ao número de folhas, novamente o substrato S6, composto por solo, diferiu-se dos demais tratamentos, por apresentar os menores valores, com amplitude mínima entre os demais tratamentos de 37,3 e $50 \%$, para as cultivares Cascade e Samambaia, respectivamente, enquanto os maiores valores foram encontrados no substrato $S 5$, composto pelas proporções de $70 \%$ SC $+20 \%$ EB $+10 \%$ CA, valores superiores de 42,8 e $70 \%$ em relação ao substrato composto por solo, para as duas cultivares, respectivamente, o qual não diferiu dos demais tratamentos compostos por resíduos alternativos (Tabela 2). O fato de o substrato composto por solo não ter apresentado bom desempenho, certamente está relacionado às características intrínsecas, físicas e químicas (Tabela 1). A casca de arroz tem alto espaço de aeração e baixa atividade química e pode ser utilizada juntamente com demais fontes orgânicas para suprimento das exigências físicas e químicas do vegetal (PERIN et al., 2018). O cultivo de tomateiro em substrato comercial composto com distintas proporções de casca de arroz, proporcionaram plantas com menor área foliar em substratos com ausência de casca de arroz e casca de arroz acima de $50 \%$ da constituição do substrato (SILVA et al., 2012). Estes resultados demonstram que o substrato deve fornecer condições adequadas para suporte da estrutura vegetal, além de proporcionar seu crescimento e desenvolvimento.
Analisando o número de frutos por planta, visualiza-se que, com exceção ao substrato S1 para a cultivar Samambaia, composto por $70 \% \mathrm{SC}+10 \% \mathrm{~EB}+10 \% \mathrm{CA}+10 \%$ $\mathrm{CC}$, o qual não diferiu do substrato $\mathrm{S} 6$, composto por solo, os substratos compostos por resíduos alternativos apresentaram os maiores valores para as cultivares, sendo que o substrato S4, composto por $60 \% \mathrm{SC}+30 \% \mathrm{~EB}+10 \%$ CA para a cultivar Cascade, e o substrato S5, composto por $70 \%$ SC $+20 \%$ EB $+10 \%$ CA para a cultivar Samambaia, apresentaram valores superiores de 565,2 e $703,7 \%$ em relação ao substrato contendo somente solo para as cultivares, respectivamente (Tabela 3). Ainda, os valores para esta variável no substrato contendo somente solo podem ser atribuídos ao teor de fósforo limitante ao desenvolvimento da planta (Tabela 1). Isto deve-se ao aspecto de que a medida que se eleva o $\mathrm{pH}$, ocorre redução da disponibilidade dos íons de fósforo, de maneira que a concentração de fósforo e nitrogênio está correlacionada positivamente com os níveis de matéria orgânica (ANJOS et al., 2015). Além de realizar a aplicação de fósforo condizente com as necessidades nutricionais, os estágios fenológicos do tomateiro também devem ser considerados, pois as exigências nutricionais são alteradas ao longo do ciclo (MUELLER et al., 2015). Nesse sentido, o decréscimo dos teores de fósforo entre os substratos resultou em menores emissões de frutos. 
Tabela 3. Número de frutos (NFR), massa fresca de frutos (MFF), diâmetro vertical de frutos (DVF), diâmetro horizontal de frutos (DHF) e produtividade (PT) de tomate cereja, cultivares Cascade e Samambaia, cultivadas em substratos alternativos (S), Itaqui, RS, 2018.

\begin{tabular}{|c|c|c|c|c|c|}
\hline \multicolumn{6}{|c|}{ Cascade } \\
\hline & NFR & MFF & DVF & DHF & PT \\
\hline substratos & & (g) & $(\mathrm{mm})$ & $(\mathrm{mm})$ & $\left(\mathrm{t} \mathrm{ha}^{-1}\right)$ \\
\hline S1 & $12,38 a^{*}$ & $6,59 a$ & $26,82 \mathrm{a}$ & $21,22 \mathrm{a}$ & $4,08 \mathrm{a}$ \\
\hline S2 & $13,75 \mathrm{a}$ & $5,91 \mathrm{ab}$ & $26,03 \mathrm{a}$ & $20,28 \mathrm{ab}$ & $4,07 a$ \\
\hline S3 & $11,63 a$ & $4,91 \mathrm{ab}$ & 23,53 a & $19,19 a b$ & $2,90 a b$ \\
\hline S4 & $16,63 \mathrm{a}$ & $4,49 \mathrm{~b}$ & $23,89 a$ & $18,48 a b$ & $3,76 \mathrm{a}$ \\
\hline S5 & 13,25 a & $6,31 a b$ & $26,73 \mathrm{a}$ & 21,28 a & $4,36 \mathrm{a}$ \\
\hline S6 & $2,50 \mathrm{~b}$ & $4,44 \mathrm{~b}$ & $24,31 \mathrm{a}$ & $17,21 \mathrm{~b}$ & $0,56 \mathrm{~b}$ \\
\hline CV (\%) & 30,75 & 16,79 & 6,75 & 7,04 & 41,88 \\
\hline \multicolumn{6}{|c|}{ Samambaia } \\
\hline S1 & $25,50 a b$ & $2,48 b$ & $15,54 \mathrm{~b}$ & $15,38 \mathrm{~b}$ & $3,15 a b$ \\
\hline S2 & 42,13 a & $2,55 \mathrm{~b}$ & $16,27 \mathrm{ab}$ & $16,17 \mathrm{~b}$ & $5,43 a$ \\
\hline S3 & 38,63 a & $3,46 \mathrm{a}$ & 17,76 a & 18,13 a & $6,84 \mathrm{a}$ \\
\hline S4 & $43,00 \mathrm{a}$ & $3,22 a b$ & $17,55 \mathrm{a}$ & $16,68 a b$ & $6,78 \mathrm{a}$ \\
\hline S5 & 45,25 a & $2,90 a b$ & $16,59 a b$ & $16,58 a b$ & $6,28 \mathrm{a}$ \\
\hline S6 & $5,63 \mathrm{~b}$ & $2,38 \mathrm{~b}$ & $15,20 \mathrm{~b}$ & $15,62 b$ & $0,67 \mathrm{~b}$ \\
\hline CV (\%) & 36,30 & 13,57 & 4,73 & 4,25 & 34,89 \\
\hline
\end{tabular}

*Médias seguidas de mesma letra minúscula na coluna não diferem entre si pelo teste de Tukey a $5 \%$ de probabilidade. S1- $70 \%$ solo $(\mathrm{SC})+10 \%$ esterco bovino (EB) $+10 \%$ casca de arroz (CA) $+10 \%$ casca de arroz carbonizada (CC); S2- $60 \%$ SC + 20\% EB + 10\% CA + 10\% CC; S3- $50 \%$ SC + 30\% EB + 10\% CA + 10\% CC; S4- 60\% SC + 30\% $E B+10 \%$ CA; S5- $70 \%$ SC + 20\% EB + 10\% CA; S6- 100\% SC.

Estes resultados demonstram que os caracteres produtivos estão intimamente relacionados aos vegetativos, pois a estatura e número de folhas também apresentaram valores inferiores para o substrato S6. Nesse sentido, substratos que promovem maiores alturas resultam em plantas mais produtivas (COSTA et al., 2015). Além disto, os caracteres produtivos estão atrelados a área foliar, sendo que a produtividade máxima é obtida quando o tomateiro se encontra com a maior área foliar (REIS et al., 2013). Logo, presume-se que, com a insuficiente produção de fotoassimilados necessários para a manutenção da planta, a disponibilidade de compostos para a emissão e desenvolvimento do fruto é reduzida, afetando negativamente a produtividade.

Observando a massa fresca dos frutos da cultivar Cascade, nota-se que o substrato S1, composto por $70 \% \mathrm{SC}+10 \% \mathrm{~EB}+10 \% \mathrm{CA}+10 \%$ $\mathrm{CC}$, não diferindo dos substratos $\mathrm{S} 2$, S3 e S5, compostos por $60 \% \mathrm{SC}+20 \% \mathrm{~EB}+10 \% \mathrm{CA}+10 \%$ CC, $70 \%$ SC $+20 \%$ EB $+10 \%$ CA e $70 \%$ SC $+20 \%$ EB $+10 \%$ CA, respectivamente, proporcionou os maiores valores para esta variável, com amplitude mínima de $34,1 \%$ aos demais tratamentos (Tabela 3). Entretanto, para a cultivar Samambaia, o substrato S3, composto por $50 \% \mathrm{SC}+30 \% \mathrm{~EB}+10 \% \mathrm{CA}+10 \% \mathrm{CC}$, não diferindo dos substratos $\mathrm{S} 4$ e $\mathrm{S} 5$, compostos por $60 \%$ SC $+30 \% \mathrm{~EB}+10 \%$ CA e $70 \% \mathrm{SC}+20 \% \mathrm{~EB}+$ $10 \% \mathrm{CA}$, respectivamente, apresentou a maior média de massa de fruto com variação mínima de $35,7 \%$ aos demais substratos (Tabela 3). Pode-se atribuir os resultados obtidos as características químicas dos substratos, sendo que os maiores valores obtidos para esta variável correspondem aos substratos com maiores teores de matéria orgânica e saturação de bases (Tabela 1).

A presença de matéria orgânica no substrato é fundamental para elevar a disponibilidade dos minerais no solo, considerando que a maioria das hortaliças cultivadas comercialmente é pouco eficiente na utilização de nutrientes (ZANDONADI et al., 2014). O aumento da matéria orgânica na composição de substratos resulta em acréscimo na disponibilidade de macronutrientes, de 
maneira que quanto maiores os teores de fósforo e nitrogênio, maior a massa dos frutos (TRUONG et al., 2018). A partir disto, a utilização de substratos a base de resíduos orgânicos mostrase benéfico a produção de frutos com mais massa, independente da fonte de resíduos orgânicos utilizada.

Os valores obtidos para os diâmetros verticais e horizontais dos frutos apresentaramse diferentes para as duas cultivares (Tabela 3). Para a cultivar Cascade, os frutos de maiores dimensões horizontais foram obtidos de tomateiros cultivados no substrato $\mathrm{S} 1$, composto por $70 \% \mathrm{SC}+10 \% \mathrm{~EB}+10 \% \mathrm{CA}+10 \% \mathrm{CC}$, o qual não se diferiu dos demais substratos compostos por resíduos alternativos, sendo que para a dimensão vertical não houve diferença entre os tratamentos. No entanto, para a cultivar Samambaia, o substrato S3, composto por 50\% $\mathrm{SC}+30 \% \mathrm{~EB}+10 \% \mathrm{CA}+10 \% \mathrm{CC}$, o qual não diferiu para o diâmetro vertical dos substrato S4 e S5, compostos por $60 \%$ SC + 30\% EB + 10\% CA e $70 \% \mathrm{SC}+20 \% \mathrm{~EB}+10 \% \mathrm{CA}$, respectivamente, além do substrato S2 para diâmetro horizontal, composto por $60 \%$ SC $+20 \%$ EB $+10 \%$ CA $+10 \%$ CC, apresentou os maiores valores, com amplitude mínima de 7,1 e 8,7\% em relação aos demais substratos, para diâmetro vertical e horizontal, respectivamente. Logo, evidencia-se que as cultivares apresentam comportamentos distintos, pois enquanto a cultivar Cascade, com exceção do substrato contendo somente solo, em substratos compostos com frações de solo, as dimensões dos frutos se sobressaíram positivamente, enquanto que para a cultivar Samambaia, os frutos de plantas cultivadas em substrato com solo na composição apresentaram os menores valores para este atributo.

As dimensões dos frutos estão atreladas ao genótipo das cultivares, bem como as condições edafoclimáticas vigentes. Esta é uma das características mais indicadas para seleção de frutos, sendo que correlacionando os diâmetros longitudinal e transversal à massa do fruto, observaram correlações positivas, logo, frutos com diâmetros longitudinal e transversal mais elevados resultam em frutos com maior massa (RODRIGUES et al., 2014). A partir desses fatores, o tamanho do fruto de tomate cereja depende da divisão e alargamento celular, além de eventos hormonais e da disponibilidade de substâncias de reserva para a manutenção do metabolismo vegetal e formação do fruto (COSTA et al., 2018b). Assim, características morfológicas do vegetal afetam diretamente a formação do fruto, pois quanto maior a desfolha durante o ciclo, menor os valores dos parâmetros dimensionais dos frutos (PERIN et al., 2018). Logo, o suprimento mineral adequado ao vegetal possibilita a constante emissão de folhas fotossintéticas ativas, além da conservação das folhas emitidas, as quais servem como síntese de fotoassimilados necessários para a formação dos frutos.

A estimação da produtividade das cultivares de tomateiro cereja podem ser visualizadas na Tabela 3, sendo que, para as duas cultivares, o substrato S6, constituído por solo, resultou em produtividades mais baixas, não diferindo do substrato S3, composto por $50 \%$ SC $+30 \% \mathrm{~EB}+10 \% \mathrm{CA}+10 \%$ CC para a cultivar Cascade, e não diferindo estatisticamente do substrato S1, composto por $70 \% \mathrm{SC}+10 \% \mathrm{~EB}+$ $10 \%$ CA + 10\% CC, para a cultivar Samambaia. Estes valores certamente estão intimamente relacionados com a emissão e a massa fresca dos frutos por planta, onde as plantas cultivadas com substratos a base de resíduos ecológicos apresentaram os maiores valores para o número e massa de frutos por planta, bem como para a produtividade. Os maiores valores produtivos do tomateiro cereja para a cultivar Cascade foi de 4,36 $\mathrm{t} \mathrm{ha}^{-1}$, obtido por tomateiros acondicionados no substrato S5, com $70 \%$ SC $+20 \%$ EB $+10 \%$ CA, e para a cultivar Samambaia, obteve-se uma produtividade de $6,84 \mathrm{t} \mathrm{ha}^{-1}$, correspondendo ao substrato S3, constituído por $50 \%$ SC + 30\% EB + $10 \% \mathrm{CA}+10 \% \mathrm{CC}$, enquanto cultivadas em substrato S6, contendo somente solo, foram de $0,56 \mathrm{t} \mathrm{ha}^{-1}$ e $0,67 \mathrm{t} \mathrm{ha}^{-1}$ para as duas cultivares, respectivamente.

Estes dados de produtividade em cultivo com substratos compostos de resíduos orgânicos apresentam-se superiores ao obtidos por Silva et al. (2019), os quais obtiveram produtividade em substratos a base de pequi de 3,1 $\mathrm{t} \mathrm{ha}^{-1}$, além do cultivo em substratos contendo somente solo, $0,30 \mathrm{t} \mathrm{ha}^{-1}$, sendo que quanto maior a proporção do solo na composição do substrato menor a produtividade. Entretanto, Albuquerque et al. (2018), avaliando o cultivo de tomate cereja da cultivar Carolina com substratos orgânicos, obtiveram valores de produtividade que variaram entre 7,63 e 15,61 t ha ${ }^{-1}$, mínimo e máximo, respectivamente. Esta variação pode ser atribuída além das características físicas, químicas e biológicas do substrato, mas também ao genótipo de cultivares, sendo mais tolerantes 
a condições desfavoráveis e, eficientes, na utilização de recursos hídricos e minerais.

A classificação dos frutos conforme as dimensões espaciais apresentaram-se de modo distinto entre as cultivares de acordo com as classes e os substratos (Tabelas 4 e 5). Para a cultivar Cascade, tomateiros cultivados em substratos que proporcionaram frutos de maior massa (Tabela 3), resultaram em frutos classificados com maiores dimensões, sendo que o substrato $\mathrm{S} 1$ composto por $70 \%$ SC $+10 \%$ EB + $10 \%$ CA $+10 \%$ CC se caracterizou por apresentar os menores valores para a classe de frutos pequenos, diferindo-se somente do substrato $\mathrm{S} 4$, composto por $60 \% \mathrm{SC}+30 \% \mathrm{~EB}+10 \% \mathrm{CA}$. Logo, a massa do fruto apresenta correlação significativa e positiva em relação ao tamanho do fruto, sendo parâmetro utilizado para a destinação do mercado consumidor e para seleção de plantas superiores (TREVISANI et al., 2017). Entretanto, para a cultivar Samambaia, não houve interação significativa entre os substratos, sendo constatado a disposição das classes de frutos conforme os substratos de modo semelhante para todos os substratos, destacando-se a elevada porcentagem de frutos classificados como descarte. Estes resultados certamente estão relacionados ao ambiente de cultivo, bem como ao genótipo das cultivares.

Sendo os frutos classificados conforme o tamanho ou peso, as quatro classes são necessárias, pois de acordo com as dimensões dos frutos estes se destinam a um nicho diferenciado de consumidores, onde o valor do fruto se eleva conforme o aumento do tamanho (FERNANDES et al., 2007). Os frutos de tomate cereja da cultivar Carolina foram atribuídos a classe pequenos, não variando conforme o cultivo em diferentes proporções dos substratos compostos por vermiculita, vermicomposto e esterco bovino (COSTA et al., 2018b). Entretanto, resultados distintos foram obtidos por Coelho et al. (2018), onde avaliando as características agronômicas de tomate cereja cultivado em substratos alternativos, constituídos por diferentes proporções de solo, cama de ave, esterco bovino e casca de arroz carbonizada, obtiveram que o substrato contendo somente solo proporcionou em sua totalidade frutos da classe gigante, não diferindo dos tratamentos compostos por $50 \%$ solo $+50 \%$ esterco bovino curtido, $50 \%$ de esterco bovino curtido $+25 \%$ solo $+25 \%$ casca de arroz carbonizada e $100 \%$ de esterco bovino curtido, sendo que os substratos compostos por $50 \%$ cama de ave $+50 \%$ solo e $25 \%$ solo $+25 \%$ esterco bovino curtido $+25 \%$ cama de ave $+25 \%$ casca de arroz carbonizada, resultaram em frutos classificados como descarte. Desta forma, o tomateiro cereja alterase morfologicamente de acordo com o ambiente de cultivo, sendo que, além do substrato, a escolha da cultivar mostra-se um parâmetro relevante para o aspecto produtivo, e principalmente, para a comercialização.

Tabela 4. Frutos de tomateiros do grupo cereja, cultivar Cascade, cultivada em substratos alternativos (S), para cada classe conforme suas respectivas dimensões em milímetros, Itaqui, RS, 2018.

\begin{tabular}{cccccccc}
\hline \multirow{2}{*}{ Classes } & \multirow{2}{*}{ Substratos } & $\mathrm{S} 1$ & $\mathrm{~S} 2$ & $\mathrm{~S} 3$ & $\mathrm{~S} 4$ & $\mathrm{~S} 5$ & $\mathrm{~S} 6$ \\
\cline { 2 - 7 } & & \multicolumn{5}{c}{ Frutos (\%) } \\
\hline gigante & $>35$ & $0,0 \mathrm{Ab} *$ & $0,0 \mathrm{Ac}$ & $0,0 \mathrm{Ab}$ & $0,0 \mathrm{Ab}$ & $7,5 \mathrm{Aa}$ & $0,0 \mathrm{Ab}$ \\
grande & $30-35$ & $14,6 \mathrm{Ab}$ & $11,1 \mathrm{Abc}$ & $0,0 \mathrm{Ab}$ & $4,8 \mathrm{Ab}$ & $17,5 \mathrm{Aa}$ & $11,8 \mathrm{Aab}$ \\
médio & $25-30$ & $58,5 \mathrm{Aa}$ & $50,0 \mathrm{Aa}$ & $38,3 \mathrm{Aa}$ & $26,2 \mathrm{Aab}$ & $32,5 \mathrm{Aa}$ & $35,3 \mathrm{Aa}$ \\
pequeno & $20-25$ & $19,5 \mathrm{Bb}$ & $33,3 \mathrm{ABab}$ & $43,8 \mathrm{ABa}$ & $57,4 \mathrm{Aa}$ & $35,0 \mathrm{ABa}$ & $29,4 \mathrm{ABab}$ \\
descarte & $<20$ & $7,4 \mathrm{Ab}$ & $5,6 \mathrm{Abc}$ & $17,9 \mathrm{Aab}$ & $9,1 \mathrm{Ab}$ & $7,5 \mathrm{Aa}$ & $23,5 \mathrm{Aab}$ \\
\hline
\end{tabular}

CV (\%) 77,03

*Médias seguidas de mesma letra maiúscula na linha e minúscula na coluna não diferem entre si pelo teste de Tukey a $5 \%$ de probabilidade. S1- $70 \%$ solo $(\mathrm{SC})+10 \%$ esterco bovino (EB) $+10 \%$ casca de arroz (CA) $+10 \%$ casca de arroz carbonizada (CC); S2- $60 \%$ SC + 20\% EB + 10\% CA + 10\% CC; S3- $50 \%$ SC + 30\% EB + 10\% CA + 10\% CC; S4- $60 \%$ SC + 30\% $E B+10 \%$ CA; S5- $70 \%$ SC $+20 \% E B+10 \% C A ; S 6-100 \%$ SC. 
Tabela 5. Frutos de tomateiros do grupo cereja, cultivar Samambaia, cultivada em substratos alternativos (S), para cada classe conforme suas respectivas dimensões em milímetros, Itaqui, RS, 2018.

\begin{tabular}{|c|c|c|c|c|c|c|c|}
\hline \multirow{2}{*}{ Classes } & \multirow{2}{*}{ Substratos $^{\text {ns }}$} & S1 & S2 & S3 & S4 & S5 & s6 \\
\hline & & \multicolumn{6}{|c|}{ Frutos (\%) } \\
\hline gigante & $>35$ & $0,0 b^{*}$ & $0,0 \mathrm{~b}$ & $0,0 \mathrm{~b}$ & $0,0 \mathrm{~b}$ & $0,0 \mathrm{~b}$ & $0,0 \mathrm{~b}$ \\
\hline grande & $30-35$ & $0,0 \mathrm{~b}$ & $0,0 \mathrm{~b}$ & $0,0 \mathrm{~b}$ & $0,0 \mathrm{~b}$ & $0,0 \mathrm{~b}$ & $0,0 \mathrm{~b}$ \\
\hline médio & $25-30$ & $2,1 \mathrm{~b}$ & $0,0 \mathrm{~b}$ & $1,6 \mathrm{~b}$ & $4,1 \mathrm{~b}$ & $1,5 \mathrm{~b}$ & $0,0 \mathrm{~b}$ \\
\hline pequeno & $20-25$ & $6,4 \mathrm{~b}$ & $10,0 \mathrm{~b}$ & $16,1 \mathrm{~b}$ & $24,5 \mathrm{~b}$ & $13,8 \mathrm{~b}$ & $0,0 \mathrm{~b}$ \\
\hline descarte & $<20$ & $91,5 \mathrm{a}$ & $90,0 \mathrm{a}$ & $82,3 \mathrm{a}$ & $71,4 \mathrm{a}$ & $84,7 \mathrm{a}$ & $100,0 \mathrm{a}$ \\
\hline
\end{tabular}

CV (\%) 66,39

*Médias seguidas de mesma letra minúscula na coluna não diferem entre si pelo teste de Tukey a $5 \%$ de probabilidade. ns- não significativo para as médias entre os substratos. S1- $70 \%$ solo (SC) $+10 \%$ esterco bovino (EB) + $10 \%$ casca de arroz (CA) $+10 \%$ casca de arroz carbonizada (CC); S2- $60 \%$ SC $+20 \%$ EB + 10\% CA + 10\% CC; S3- 50\% SC + $30 \% E B+10 \%$ CA $+10 \%$ CC; S4- $60 \%$ SC $+30 \%$ EB + 10\% CA; S5- 70\% SC + 20\% EB + 10\% CA; S6- $100 \%$ SC.

\section{Conclusões}

O crescimento e a produtividade de tomateiro cereja modificam-se conforme as características dos substratos. Os substratos compostos de resíduos obtidos do beneficiamento do arroz e dejetos de bovinos resultaram em tomateiros com os melhores valores para todos os parâmetros avaliados na fase vegetativa e reprodutiva das duas cultivares de tomate cereja. Os substratos elaborados a base de resíduos alternativos de base ecológica mostram-se como fontes alternativas e interessantes no cultivo do tomateiro visando o reaproveitamento da matéria e a sustentabilidade do sistema produtivo.

\section{Referências}

ALBUQUERQUE, E. M.; LIMA, I. L.; SOUZA, N. S.; LEÃO, F. A. N.; CONCEIÇÃO, H. E. O. Produção de biomassa e produtividade do tomateiro cv. Carolina em diferentes substratos, sob ambiente protegido. Enciclopédia Biosfera, v. 15, n. 27, p. 244-253, 2018.

http://dx.doi.org/10.18677/EnciBio 2018A69

ANJOS, D. C.; HERNANDEZ, F. F. F.; COSTA, J. M. C.; URQUIAGA CABALLERO, S. S.; MOREIRA, V. O. G. Fertilidade do solo, crescimento e qualidade de frutos do mamoeiro Tainung sob fertirrigação com potássio. Revista Ciência Agronômica, v. 46, n. 4, p. 774-785,

2015.

http://dx.doi.org/10.5935/1806-

\section{$\underline{6690.20150065}$}

BARANKEVICZ G. B.; NOVELLO D.; RESENDE J. T. V.; SCHWARZ K.; SANTOS E. F. Características físicas e químicas da polpa de híbridos de tomateiro, durante o armazenamento congelado. Horticultura Brasileira, v. 33, n. 1, p. 7-11, 2015. http://dx.doi.org/10.1590/S0102$\underline{053620150000100002}$

COELHO, R. G.; OLIVEIRA, F. D. F.; SOUZA, E. B.; AZEVEDO, J. M. A.; LIMA, M. O. Desenvolvimento e características produtivas de tomate do tipo cereja em diferentes compostos orgânicos. Revista Espacios, v. 29, n. 26, 2018.

COSTA, A. M.; COSTA, A. R.; SILVA, W. M.; SILVA, P. O.; COSTA, G. M.; SILVA, F. F. Produção do tomate cereja em diferentes compostos orgânicos e sua aplicabilidade na agricultura familiar. Global Science and Technology, v. 11, n. 3, p. 20-36, 2018a.

COSTA, E.; BINOTTI, F. S.; CARDOSO, E. D.; LIMA JÚNIOR, D. B.; ZOZ, T.; ZUFFO, A. M. Cherry tomato production on different organic substrates under protected environment conditions. Australian Journal of Crop Science, v. 12 , n. 1, p. 87-92, 2018b.

http://dx.doi.org/10.21475/ajcs.18.12.01.pne749

COSTA, E.; SANTO, T. L. E.; SILVA, A. P.; SILVA, L. E.; OLIVEIRA, L. C.; BENETT, C. G. S.; BENETT, K. S. $S$. Ambientes e substratos na formação de mudas e produção de frutos de cultivares de tomate cereja. Horticultura Brasileira, v. 33, n. 1, p. 110118, 2015. http://dx.doi.org/10.1590/S0102$\underline{053620150000100018}$ 
DIAS, D. M.; RESENDE, J. T. V.; ZEIST, A. R.; GABRIEL, A.; SANTOS, M. H.; RESENDE, N. C. V.; GUERRA, E. P Resistance of processing tomato genotypes to leafminer (Tuta absoluta). Horticultura Brasileira, v. 37, p. 40-46, 2019. http://dx.doi.org/10.1590/s0102-053620190106

Empresa Brasileira de Pesquisa Agropecuária (EMBRAPA). Sistema brasileiro de classificação de solos. 5. ed. Rio de Janeiro: EMBRAPA, 2018. $356 \mathrm{p}$.

FERNANDES, C.; CORÁ, J. E.; BRAZ, L. T. Classificação de tomate-cereja em função do tamanho e peso dos frutos. Horticultura Brasileira, v. 25, n. 2, p. 275-278, 2007. http://dx.doi.org/10.1590/S0102-

$\underline{05362007000200029}$

FERREIRA, A. K. D.; DIAS, N. S.; SOUSA JUNIOR, F. S.; FERREIRA, D. A. C.; FERNANDES, C. S.; LEITE, T. S. Composting of household organic waste and its effects on growth and mineral composition of cherry tomato. Revista Ambiente \& Água, v. 13, n. 3, p. 1-11, 2018.

http://dx.doi.org/10.4136/ambi-agua.2141

FERREIRA, D. F. SISVAR: um programa para análises e ensino de estatística. Revista Symposium, v. 6, n. 2, p. 36-41, 2008.

LUCINI, T.; RESENDE, J. T.; OLIVEIRA, J. R.; SCABENI, C. J.; ZEIST, A. R.; RESENDE, N. C. Repellent effects of various cherry tomato accessions on the two-spotted spider mite Tetranychus urticae Koch (Acari: Tetranychidae). Genetics and Molecular Research, v. 15, n. 1, 2016. http://dx.doi.org/10.4238/gmr.15017736

LUZ, J. M. Q.; SHINZATO, A. V.; SILVA, M. A. D. Comparação dos sistemas de produção de tomate convencional e orgânico em cultivo protegido. Bioscience Journal, v. 23, n. 2, p. 7-15, 2007.

MACIEL, G. M.; FERNANDES, M. A. R.; MELO, O. D.; OLIVEIRA, C. S. Potencial agronômico de híbridos de minitomate com hábito de crescimento determinado e indeterminado. Horticultura Brasileira, v. 34, n. 1, p. 144-148, $2016 . \quad$ http://dx.doi.org/10.1590/S0102$\underline{053620160000100022}$
MUELLER, S.; SUZUKI, A.; WAMSER, A. F.; VALMORBIDA, J.; FELTRIM, A. L.; BECKER, W. F. Modos de aplicação de fósforo para duas cultivares de tomate. Horticultura Brasileira, v. 33, n. 3, p. 356-361, 2015.

http://dx.doi.org/10.1590/S0102$\underline{053620150000300013}$

NASCIMENTO, A. R.; SOARES JÚNIOR, M. S.; CALIARI, M.; FERNANDES, P. M.; RODRIGUES, J. P. M.; CARVALHO, W. T. Qualidade de tomates de mesa cultivados em sistema orgânico e convencional no estado de Goiás. Horticultura Brasileira, v. 31, n. 4, p. 628-635, 2013. http://dx.doi.org/10.1590/S0102$\underline{05362013000400020}$

PERIN, L.; PEIL, R. M. N.; HOHN, D.; ROSA, D. S. B.; WIETH, A. R.; GROLLI, P. R. Trough and pot crop systems with leaching recirculation and defolation levels for mini tomatoes. Acta Scientiarum. Agronomy, v. 40, n. 1, p. 1-8, 2018. http://dx.doi.org/10.4025/actasciagron.v40i1.349 $\underline{92}$

REIS, L. S.; AZEVEDO, C. A. V.; ALBUQUERQUE, A. W.; SOUZA JUNIOR, J. F. Índice de área foliar e produtividade do tomate sob condições de ambiente protegido. Revista Brasileira de Engenharia Agrícola e Ambiental, v. 17, n. 4, p. 386-391, 2013.

RODRIGUES, F. A.; PENONI, E. S.; SOARES, J. D. R.; SILVA, R. A. L. S.; PASQUAL, M. Caracterização física, química e físico-química de physalis cultivada em casa de vegetação. Ciência Rural, v. 44, n. 8, p. 1411-1414, 2014.

http://dx.doi.org/10.1590/0103-8478cr20130743

SANTOS, P. L. F.; SILVA, O. N. M.; PAIXÃO, A. A.; CASTILHO, R. M. M. Germinação e desenvolvimento de mudas do tomateiro cereja em diferentes substratos. Tecnologia \& Ciência Agropecuária, v. 11, n. 5, p. 41-45, 2017.

SCALCO, A. R.; PIGATTO, G. A. S.; SOUZA, R. Commercialization channels of organic products in Brasil: analysis at the first level of the production chain. Gestão \& Produção, v. 24, n. 4, p. 777-789, 2017.

http://dx.doi.org/10.1590/0104-530x2189-16

SILVA, R. R.; RODRIGUES, L. U.; FREITAS, G. A.; MELO, A. V.; NASCIMENTO, I. R.; D'ANDRÉA, A. F. 
Influência de casca de arroz carbonizada em diferentes substratos na qualidade de mudas de tomateiro. Revista Brasileira de Ciências Agrárias, v. 7, p. 803-809, 2012.

http://dx.doi.org/10.5039/agraria.v7isa2227

SILVA, T. I.; FEITOSA, A. J. S.; MACIEL, T. C. M. FIGUEIREDO, F. R. A.; MARCO, C. A. Produtividade de tomate cereja (Solanum lycopersicon) em função da adubação orgânica à base de pequi (Caryocar coriaceum). Acta Iguazu, v. 8, n. 1, p. 50-59, 2019.

TREVISANI, N.; MELO, R. C.; COLLI, M. P.; COIMBRA, J. L. M.; GUIDOLIN, A. F. Associations between traits in fisális: a tool for indirect selection of superior plants. Revista Brasileira de Fruticultura, v. 39, n. 4, p. 1-7, 2017.

http://dx.doi.org/10.1590/0100-29452017106

TRUONG, H. D.; WANG, C. H.; KIEN, T. T. Effect of vermicompost in media on growth, yield and fruit quality of cherry tomato (Lycopersicon esculentun Mill.) under net house conditions. Compost Science \& Utilization, v. 26, n. 1, p. 52-58, 2018. http://dx.doi.org/10.1080/1065657X.2017.13445 $\underline{94}$

WANG, X.; ZHAO, F.; ZHANG, G.; ZHANG, Y.; YANG, L. Vermicompost improves tomato yield and quality and the biochemical properties of soils with different tomato planting history in a greenhouse study. Frontiers in Plant Science, v. 8, article 1978, p.1-12, 2017. http://dx.doi.org/10.3389/fpls.2017.01978

ZANDONADI, D. B.; SANTOS, M. P.; MEDICI, L. O.; SILVA, J. Ação da matéria orgânica e suas frações sobre a fisiologia de hortaliças. Horticultura Brasileira, v. 32, n. 1, p. 14-20, 2014.

http://dx.doi.org/10.1590/S0102-

$\underline{05362014000100003}$

ZANIN, D. S.; RESENDE, J. T. V.; ZEIST, A. R.; OLIVEIRA, J. R. F.; HENSCHEL, J. M.; LIMA FILHO, R. B. Selection of processing tomato genotypes resistant to two spotted spider mite. Horticultura Brasileira, v. 36, p. 271-275, 2018. http://dx.doi.org/10.1590/s0102-053620180221

ZEIST, A. R.; GIACOBBO, C. L.; SILVA NETO, G. F.; ZEIST, R. A.; DORNELES, K. R.; RESENDE, J. T. V. Compatibility of tomato cultivar Santa Cruz Kada grafted on different Solanaceae species and control of bacterial wilt. Horticultura Brasileira, v. 36, n. 3, p. 377-381. 2018.

http://dx.doi.org/10.1590/\$0102053620180315

ZEIST, A. R.; RESENDE, J. T. V.; POZZEBON, B. C.; GABRIEL, A.; SILVA, A. A.; ZEIST, R. A. Combination of solarization, biofumigation and grafting techniques for the management of bacterial wilt in tomato. Horticultura Brasileira, v. 37, n. 3, p. 250-255, 2019.

http://dx.doi.org/10.1590/S0102-05362019020 